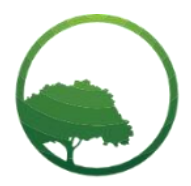

Research in Business \& Social Science

IJRBS VOL 10 NO 4 ISSN: 2147-4478

\title{
Coach training: Impact beyond coach training
}

\author{
(D) Maroushka Gupta (a) (iD) Ashwaria Gupta (b) (D) Rajat Garg (c) (D) Ruchi Agrawal ${ }^{(d)}$ \\ (a) Research Associate, Coach-to-Transformation \\ (b) MD.,Leadership Coach, Coach-to-Transformation \\ (c) Co-founder, Coach-to-Transformation \\ ${ }^{(d)}$ Director-Operations, Coach-to-Transformation
}

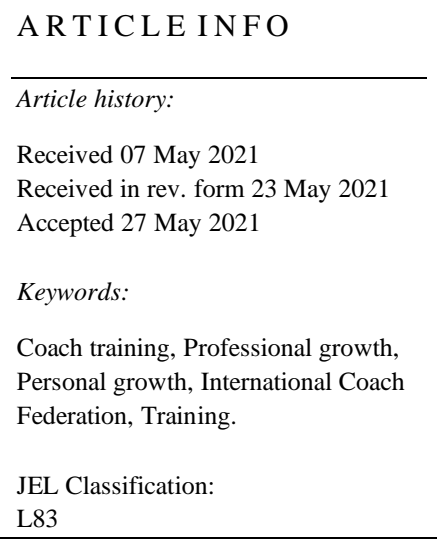

\begin{abstract}
A B S T R A C T
The aim of this study is to know the impact of coach training on coaches' personal and professional lives in various areas of development. A self-report questionnaire and an interview methodology were used to collect data using a within-subject design. The results of the study show that there is a significant improvement in the various areas of development impacting both the personal and professional life of the coach in a positive manner. The practical implications of the study are further discussed.
\end{abstract}

(C) 2021 by the authors. Licensee SSBFNET, Istanbul, Turkey. This article is an open access article distributed under the terms and conditions of the Creative Commons Attribution (CC BY) license (http://creativecommons.org/licenses/by/4.0/).

\section{Introduction}

Coaching can be defined as a process in which a coach and the person being coached (usually refereed as coachee) form a relationship to undergo a process of introspection. This helps the coachee unfold his/her potential and as well as enhance their personal and professional skills. The process of Coaching takes patience, trust and understanding so that the person being coached is given sufficient time to arrive at his/her own conclusion rather than giving them direct solution.

A Coach plays an instrumental role in creating self-awareness and self-responsibility in the person being coached and establishes a committed relationship with his/her client that is completely based on foundation of understanding and trust. According to the worldrenowned philosopher and psychiatrist, Alfred Adler, an individual is responsible for creating his/her own destiny by striving towards finding meaning and goal to create a purposeful life.

Coaching is a journey that people embark upon to unlock their true potential and this process helps them achieve their goals. It enables people to become the most focussed and productive version of themselves. Over the years, the coaching industry has constantly matured and developed and it has got immense potential for further growth as well as there is not enough data to work upon. Coach training on the other hand is a process wherein people undergo a structured program/curriculum to develop their coaching skills. Going through such a program which is recognized and approved by an international body like International Coach Federation (ICF) adds credibility to a coach's credentials.

The main objective of this study is to find out the kind of influence Coach Training has and how it has impacted an individual beyond the coach training process, this was done by analysing various aspects of a person's life which were categorized into self- awareness, life - enhancers and levels of functioning. This was done in order to bridge the gap in terms of lack of data available and have a better understanding of how the process of coach training impacts an individual.

* Corresponding author. ORCID ID: 0000-0002-5350-4240

(C) 2021 by the authors. Hosting by SSBFNET. Peer review under responsibility of Center for Strategic Studies in Business and Finance.

https://doi.org/10.20525/ijrbs.v10i4.1170 


\section{Literature Review}

According to the International Coach Federation (ICF) 2016 Global Coaching Study, the coaching industry continues to show growth as a response to workplace demands (De Meuse, Dai \& Lee, 2009; Turner \& Hawkins, 2016). The coaching industry needs to be serving both to the individual as well as the organisation in ways that demonstrate clear value (Schlosser, Steinbrenner, Kumata, \& Hunt, 2007).

Coach training Program helps not only an individual to become an accredited and qualified Coach but also its learnings can be used by the coach in his/her day-to-day personal and professional life.

The quality of Coach Training and the Coaching skills acquired during the course of the training has a major influence on the practice of Coaching and on the person being coached. However, it is also extremely important to consider the kind of impact Coach training has on a person and its relevance in their personal and professional lives. In the world of coaching, clients expect to get coached by a 'certified' or an 'accredited' coach. According to a survey by the International Coach Federation(ICF), $84 \%$ of coaching clients said coaching credentials of the coach were 'important' or 'very important' to them.

People are increasingly becoming aware of the value that coaching adds in achieving their personal and professional goals. Studies have shown that over 80 percent of clients who had been part of a coaching relationship in the past stated it was important for coaches to be accredited. The ICF or the International Coaching Federation is a Global body which has over 30,000 accredited members practicing in various corners of the world. The ICF has been accrediting coaches since 1998 and ICF certifications have come to denote a gold standard in Coach training and accreditation (2017 ICF).

According a study conducted by Harvard Business Review, organizations are no longer using the traditional command and control practices, instead they are engaging more in giving support and guidance rather than focusing on the instructional environment. This new environment focuses on enabling employees to unfold their potential, innovation and commitment, this shift in trend open up doors for coach training in organisations to support their employees to reach their goals. To understand the effect of duration of time on the process of coach training on the client a comparative study was done by Grant (2007) to understand the effect of a short term ( 2 days)- and a long term (13 days) coaching skills training programme on its trainees. This study by Grant demonstrated that a short intensive training programme is as effective as a long duration programme in terms of goal focusing however, in order to increase underlying emotional intelligence of trainees, a longer spaced-out learning approach is essential.

There is a significant amount of gap with reference to past researches conducted in the area of coach training. While numerous studies across populations have been conducted on benefits of coaching, negligible data is available on the process of undergoing training to be a coach; fewer than 30 per cent of such programmes are evaluated in any way at all (Grant MA, 2007). It is vital to consider the well-being of any professional coach in order to ensure that their services are effective, free of biases, not a projection of the coach's own insecurities and other barriers that are likely to come in the way of the well-being of a client seeking help. The present study is a stepping stone towards bridging the gap in this area of research and is based on an exploratory research method. The objective of the study is to assess impact of coach training programs beyond coach training. It highlights specific areas of development of a participant's life and helps in gathering evidence to understand the effects of coach training on these areas of development and on one's personal and professional life.

\section{Methodology}

A qualitative research was conducted to understand how Coach Training impacts the life of the participants in different areas of development as well as reflection of these areas of development in their professional and personal lives. The current research methodology allowed the researcher to make use of techniques such as grounded theory and case study wherever required. The chosen areas of development were grouped under 3 major pillars namely Self- Awareness, Life Enhancers and Level of Functioning.

Self-aware people understand what motivates them and their decision-making. They recognize their feelings (as they happen) and how it affects their thoughts. They understand their strengths and weaknesses. Self-aware people realize their proclivity to bias and blind spots. As rightly said, self-awareness is a trinity: "Know thyself, improve thyself, and complement thyself". As a result, selfawareness was chosen as one of the pillars which was further divided into 10 areas of development namely blind spots, empathy, biases, clarity on purpose, value system, beliefs, perception, behaviors and assumption.

The next pillar was called as 'Life Enhancers', which was further divided into seven areas of development that is trust, curiosity, empowerment, motivation, confidence, optimism, relationships. These areas of development if reflected upon can make a huge difference in people's lives and their performances. These behaviours work together to enrich peoples' lives and can be called as 'Life Enhancers'.

The core skills of coaching can be divided into mental and interpersonal skills. The mental skills include observation and analysis, and the ability to structure the coaching process for the person being coached. Key interpersonal skills include questioning; listening; giving and receiving feedback; communicating and motivating. On the basis of this the third pillar was labelled as Level of Functioning, which further consisted of eight areas of development viz. thinking, listening, planning, executing, exploring, learning, understanding, opening up and sharing. Individuals are much more likely to regard change in a positive light if they associate change 
with learning and personal development. All these different levels of functioning (not in any hierarchy) act together to advance the functioning of a good coach. These levels not only enable people to acquire effective coaching skills but also help them to lead a more meaningful life.

Majority people who train to become coaches do so with an intention of having a positive impact on others and to be able to help others. However, reasons need not be entirely altruistic because the skills one learns while training to be a coach could have a positive impact on the Coach's own life as well in addition to others' lives. The present study focuses on how these changes impacted the client's personal and professional lives through the telephonic interview.

In order to ensure smooth functioning, the entire study was divided into two phases which are as follows.

\section{Phase 1}

The study was conducted to understand how Coach Training is not only about enabling individuals to equip themselves with coaching skills but also about supporting individuals to increase their self-awareness, level of functioning and life enhancing behaviours along with creating a positive impact in their personal and professional lives. Thus, in the first phase of the study a survey was administered to the participants who had undergone coach training. The details of the adopted survey method are as follows-

Participants : Data was collected from 101 participants who had undergone coach training from various recognized coaching organizations including Coach-To-Transformation. Out of these participants, 26 participants were between the age group of 18 - 40 years old, 63 were between the age group of 40-60 years old and 12 were from the age group of 60 years and above. Participants for the study were selected through convenient sampling.

Design: A within-subjects design was used. Data was gathered using a self-report survey. The aim of the survey was to find out how Coach Training helped the participants to make a progress in different areas of development belonging to the 3 pillars and how it had an impact on the participant's personal and professional life. This was done by analysing the progress made by participants in three different pillars namely Self- Awareness (SA), Life Enhancers (LE) and Level of Functioning (LoF) which further included the 24 areas of development as subcategories (refer to Table 1). This self-report survey was sent via email to all the participants. Later a telephonic interview was also conducted with the participants to gather qualitative responses on the overall experience of the participants in coach training.

\section{Procedure}

Table 1 displays how the 24 areas of development were divided into the three pillars of Self- awareness, Life enhancers and Levels of Functioning in the self- report survey which was used by the participants to score themselves.

Table 1: Division of the 24 areas of development into 3 pillars.

\begin{tabular}{lll}
\hline Self-Awareness & Life Enhancers & Levels of Functioning \\
\hline Blind spots & Motivation & Thinking \\
\hline Empathy & Confidence & Listening \\
\hline Biases & Optimism & Planning \\
\hline Clarity on purpose & Trust & Executing \\
\hline Emotional state & Curiosity & Exploring \\
\hline Value system & Empowerment & Learning \\
\hline Beliefs & Relationships & Understanding \\
\hline Perceptions & & Opening up and sharing \\
\hline Assumptions & & \\
\hline Behaviours & & \\
\hline
\end{tabular}

\section{Instructions to the participants}

Participants were instructed to select 3 areas of development from each of the 3 main pillars namely Self- awareness, Life enhancers and Levels of Functioning, in which they believed to have made the most progress as a result of undergoing the coach training process. In the next step participants were asked to rate themselves on a 10-point Linear Numeric Scale (where 0 indicates Very Low and 10 indicates Very High) in these nine areas of development (three areas of development were selected from each of the three categories) that they had selected from each of the three pillars of Self-Awareness, Life Enhancers and Life of Functioning. Participants had to indicate where they stood on a given area of development before undergoing coach training and after undergoing coach training, for example, if a participant selected Clarity of purpose as one of the areas of development from the pillar of Self Awareness and scored themselves to be at 4.35- points before training and 7.98-points after training, now this will imply that there was an improvement of 3.63-points in the given participant's area of Clarity on Purpose as a result of undergoing coach training.

The next part of the survey asked the participants to report the impact of coach training on their personal and professional lives. A three-point Likert Scale was used (Low, Moderate, High) in this section. 


\section{Results}

\section{Impact of Self- Awareness beyond coach training:}

At the heart of Coaching framework lies self-awareness. Self-awareness is the ability to focus our attention on ourselves and see self clearly through reflection and introspection. It helps evaluate our current behaviour to our internal standards and values. Selfawareness is the first step to be able to help others. This make it extremely crucial for a Coach to be self-aware for him to be able to coach others. Coaching skills and emotional intelligence are inextricably related. For a successful coaching engagement both the Coach and the person being coached should be able to regulate their emotions (Grant 2007). According to the data collected in the present study it was observed that $44.55 \%$ participants selected Assumptions, $42.57 \%$ selected Clarity on Purpose and $37.62 \%$ selected Emotional State as areas of development in the pillar of self- awareness indicating that a large proportion of the population preferred these areas of development to report maximum growth/improvement in (Refer to figure 1 for complete data).

\section{Self-Awarness}

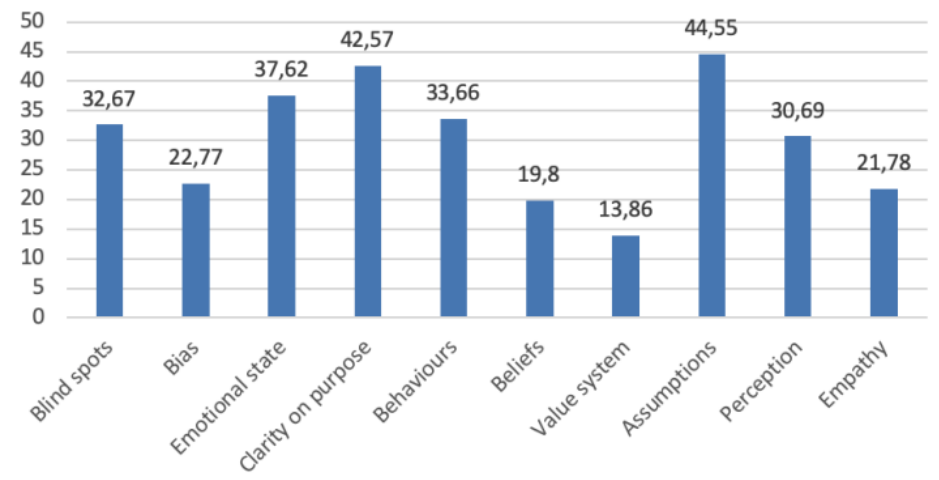

Figure 1: percentage of people selecting the various Areas of development in the pillar of self - awareness.

The average score of participants on Assumptions before coach training was 4.44 and after coach training was 7.69, indicating an improvement of 3.35 points. The average score of participants on Clarity on Purpose before and after coach training were 4.35 and 7.98 respectively, resulting in an improvement of 3.63 points. The average score of participants on Emotional State before coach training was 4.68 and after coach training was 7.92 , indicating an improvement of 3.24 points. (Refer to Figure 2 for complete data)

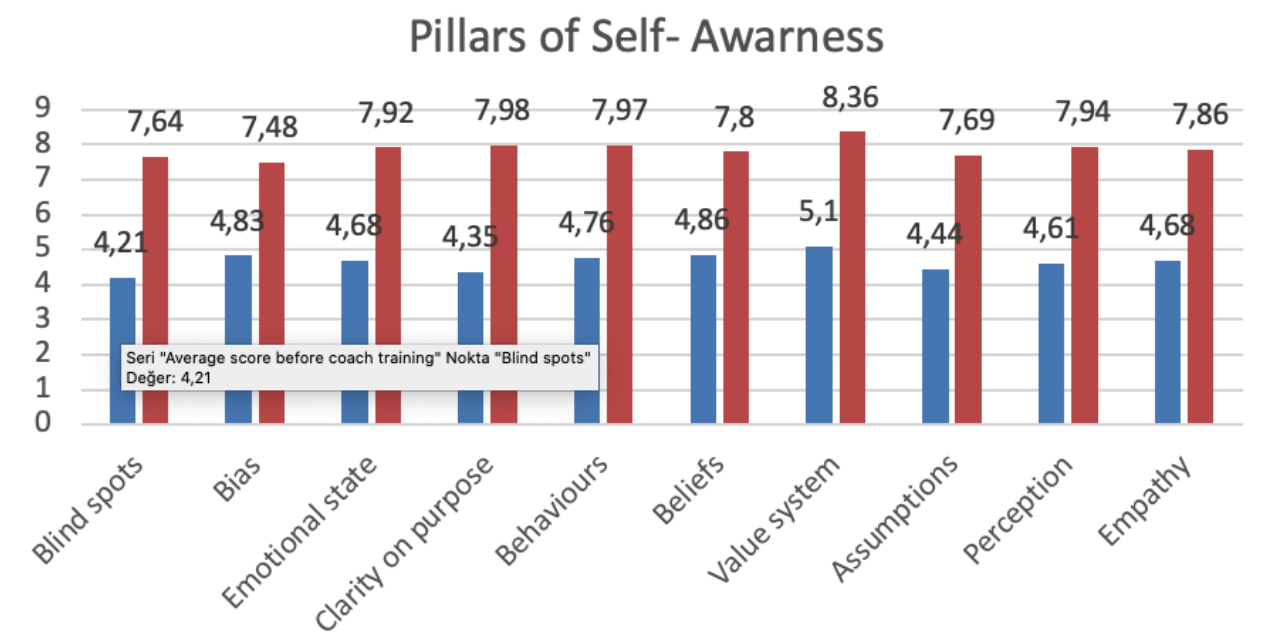

Average score before coach training

average score after coach training

Figure 2: Average score in the areas of development belonging to the self- awareness pillar before and after coach training. 


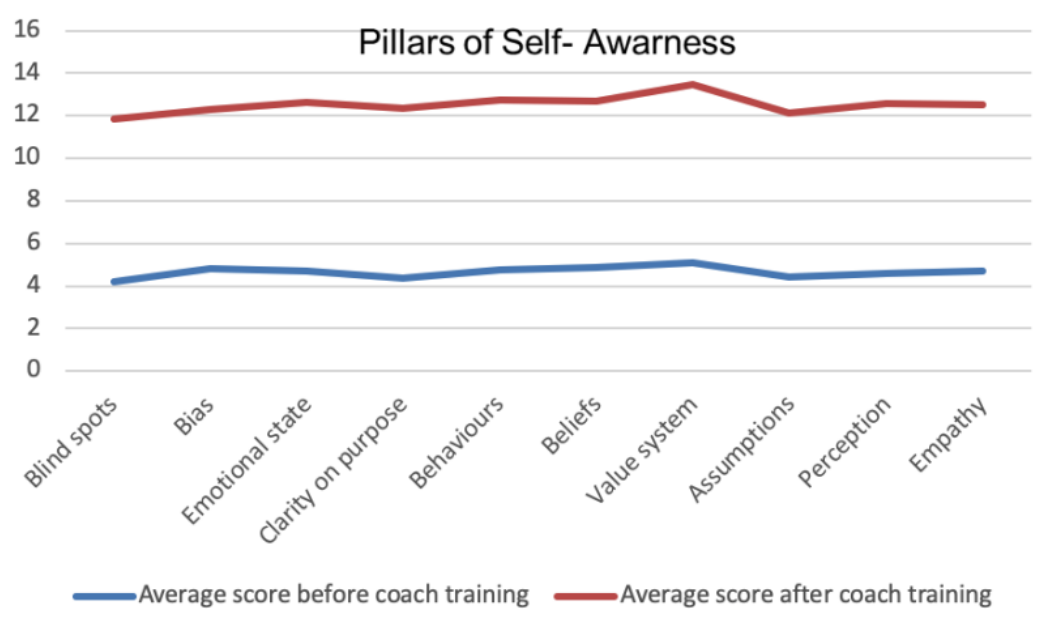

Figure 2 (b): Pillars of self- awareness pillar before and after coach training.

\section{Impact of Life Enhancers beyond coach training:}

The study collected the data to know the impact of coach training on the different Life enhancing behaviours and it was observed that $56.44 \%$ participants selected Confidence, $52.48 \%$ selected Curiosity and $49.50 \%$ selected Relationships as their preferred areas of development. (Refer to Figure 3 for complete data)

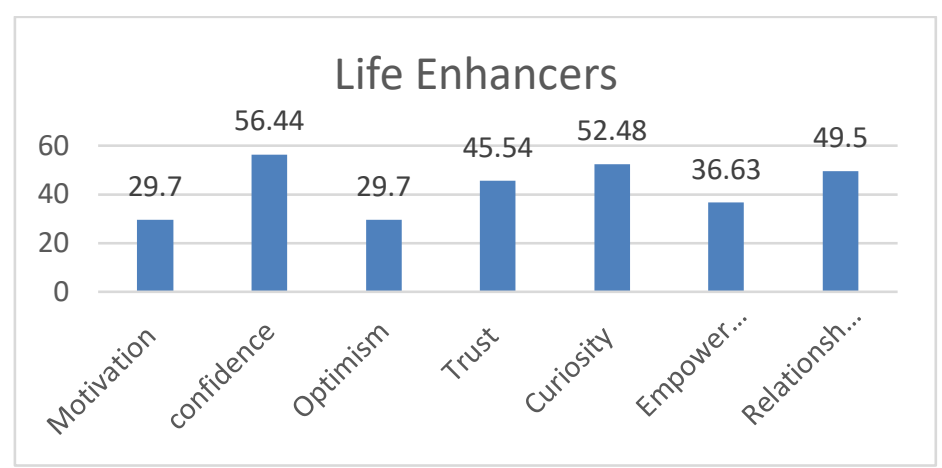

Figure 3: Percentage of people selecting the various areas of development in the pillar of Life Enhancers.

The average score of participants on Confidence before coach training was 5.46 and after coach training was 8.04, an improvement of 2.58 points. The average score of participants on Curiosity was 4.60 and after coach training was 7.87 , an improvement of 3.27 points. The average score of participants on Relationships before coach training was 5.34 and after coach training was 8.08 , an improvement of 2.74 points. (Refer to figure 4 for complete data)

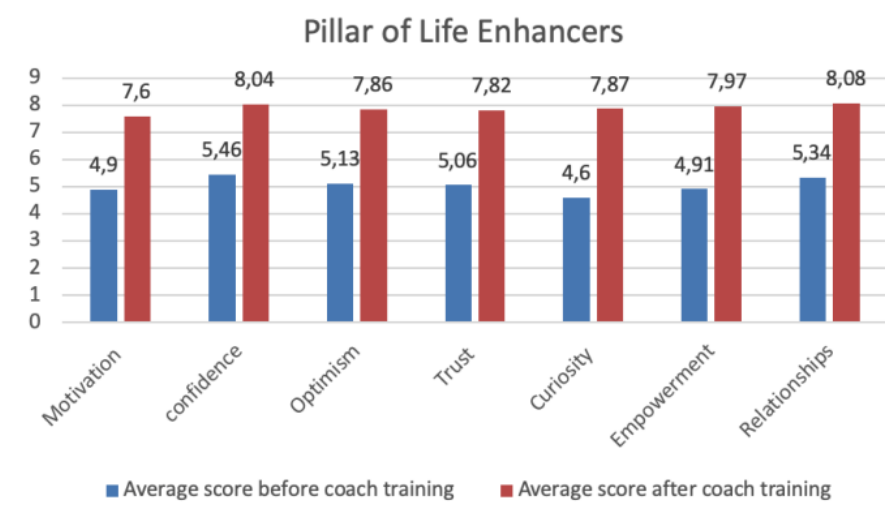

Figure 4: Average score in the areas of development belonging to the Life Enhancers' pillar before and after coach training. 


\section{Pillar of Life Enhancers}

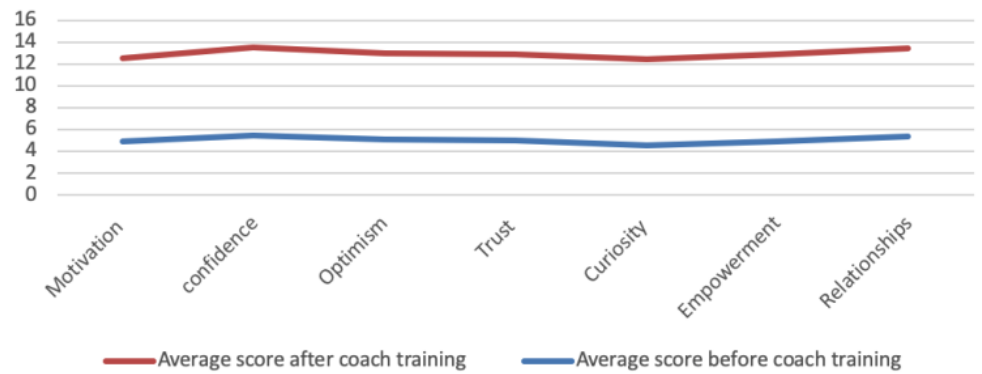

Figure 4(b): Pillar of Life Enhancers

\section{Impact of Levels of Functioning beyond coach training:}

Under the pillar of Levels of Functioning $89.11 \%$ participants selected Listening, $60.40 \%$ selected Exploring and $41.58 \%$ selected Understanding as their preferred areas of development. (Refer to figure 5 for complete data)

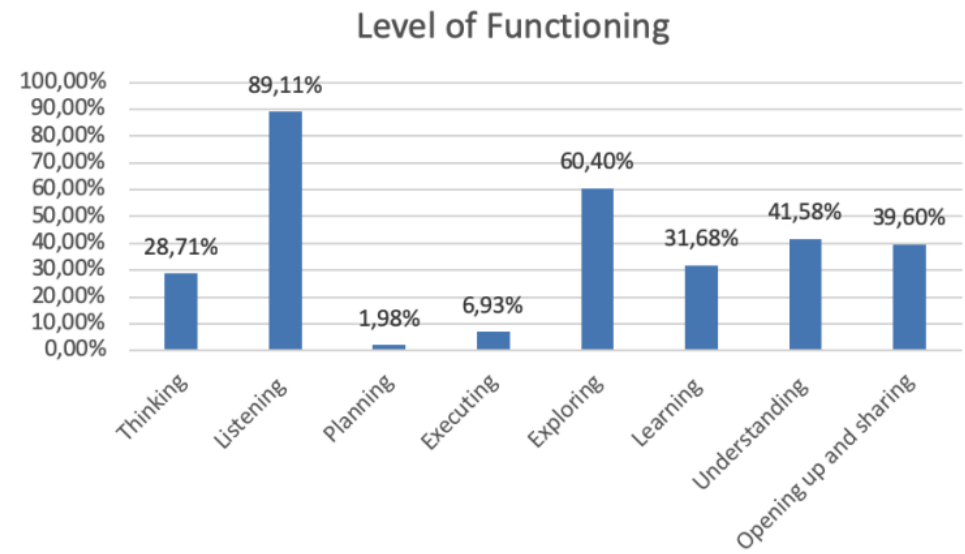

Figure 5: Percentage of people selecting the various areas of development in the pillar of Level of Functioning.

The average score of participants on Listening before coach training was 4.49 and after coach training was 7.77, an improvement of 3.28 points. The average score of participants on Exploring was 4.26 and after coach training was 7.72, an improvement of 3.46 points. The average score of participants on Understanding before coach training was 5.07 and after coach training was 7.59, an improvement of 2.52 points. (Refer to figure 6 for complete data)

\section{Pillars of Levels of Functioning}

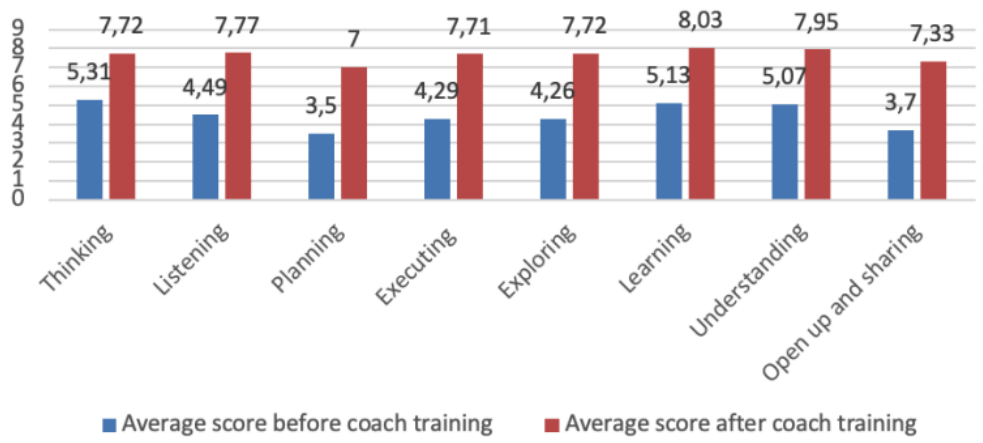

Figure 6: Average score in the areas of development belonging to the Level of Functioning pillar before and after coach training. 


\section{Pillars of Levels of Functioning}

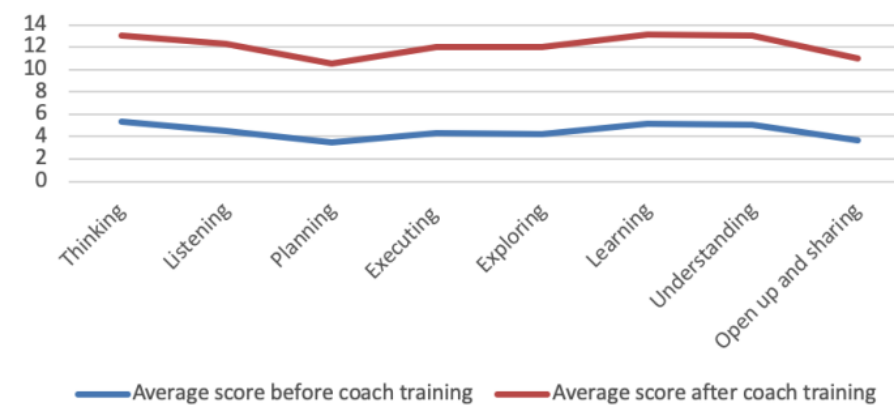

Figure 6: Levels of Functioning pillars

The results for other areas of development in terms of number of people opting for that area of development and perceived improvement in the score by using the self-report survey is also shown in tables 2,3 , and 4 .

Table 2: Data for the areas of development of Self-awareness pillar.

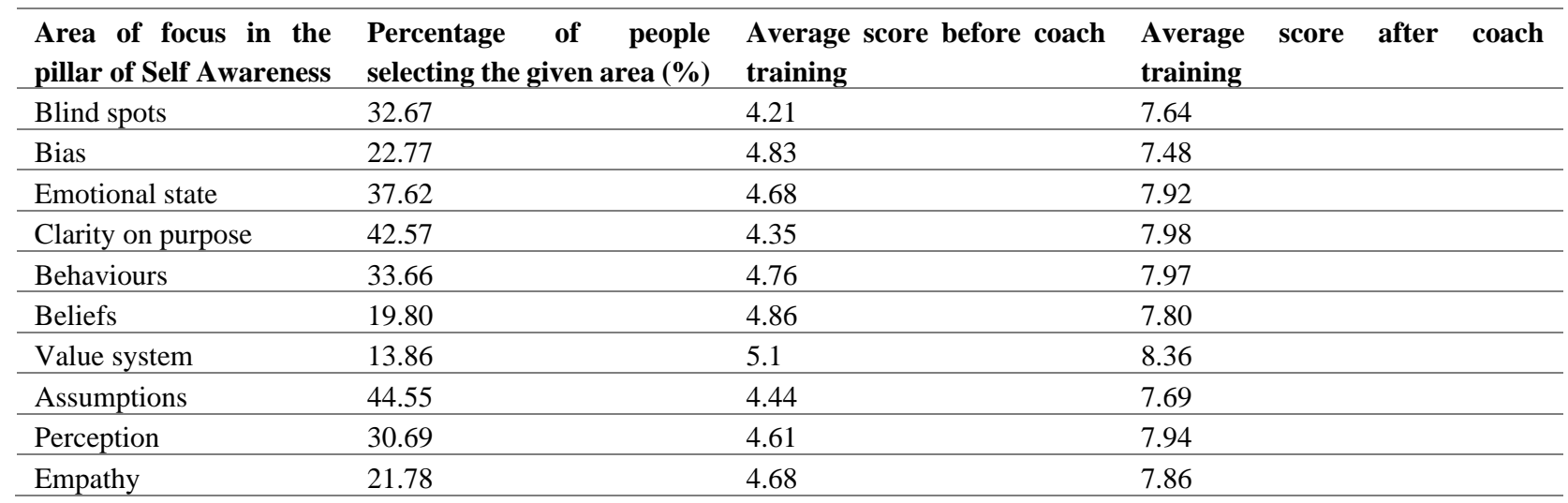

Table 3: Data for the areas of development of Life- Enhancers pillar

\begin{tabular}{llll}
\hline $\begin{array}{l}\text { Area of focus in the } \\
\text { pillar of Life Enhancers }\end{array}$ & $\begin{array}{l}\text { Percentage of people } \\
\text { selecting the given area (\%) }\end{array}$ & $\begin{array}{l}\text { Average score before coach } \\
\text { training }\end{array}$ & $\begin{array}{l}\text { Average } \\
\text { training }\end{array}$ \\
\hline Motivation & 29.70 & 4.90 & 7.60 \\
\hline confidence & 56.44 & 5.46 & 8.04 \\
\hline Optimism & 29.70 & 5.13 & 7.86 \\
\hline Trust & 45.54 & 5.06 & 7.82 \\
\hline Curiosity & 52.48 & 4.60 & 7.87 \\
\hline Empowerment & 36.63 & 4.91 & 7.97 \\
\hline Relationships & 49.50 & 5.34 & 8.08 \\
\hline
\end{tabular}

Table 4: Data for the areas of development of Levels of Functioning pillar.

\begin{tabular}{llll}
\hline $\begin{array}{l}\text { Area of focus in the } \\
\text { pillar of Levels } \\
\text { Functioning }\end{array}$ & $\begin{array}{l}\text { Percentage of people } \\
\text { selecting the given area }(\%)\end{array}$ & $\begin{array}{l}\text { Average score before coach } \\
\text { training }\end{array}$ & $\begin{array}{l}\text { Average } \\
\text { training }\end{array}$ \\
\hline Thinking & 28.71 & 5.31 & 7.72 \\
\hline Listening & 89.11 & 4.49 & 7.77 \\
\hline Planning & 1.98 & 3.50 & 7 \\
\hline Executing & 6.93 & 4.29 & 7.71 \\
\hline Exploring & 60.40 & 4.26 & 7.72 \\
\hline Learning & 31.68 & 5.13 & 8.03 \\
\hline Understanding & 41.58 & 5.07 & 7.95 \\
\hline Open up and sharing & 39.60 & 3.70 & 7.33 \\
\hline
\end{tabular}


Majority people who train to become coaches do so with an intention of having a positive impact on others, to be able to help others. However, reasons need not be entirely altruistic because the skills one learns while training to be a coach could have a positive impact on Coach's own life as well as others' lives. Being able to listen with curiosity, reflect with accuracy, question effectively and provide constructive feedback are skills that could transform Coach's own personal and professional life as well.

\section{Impact on Personal Life}

Through the telephonic interview process with the participants who had undergone the coach training process it was observed that 93.06\% participants reported a Moderate to High impact of coach training on their personal lives. Wherein participants who had experienced high impact in their personal lives reported highest improvement in the areas of development such as Clarity of Purpose, Emotional State, Behaviours and Blind Spots from the category of Self- Awareness. In the pillar of Life Enhancers these participants found maximum impact in areas of Confidence, Relationships and Curiosity. Whereas in the pillar of Level of Functioning after undergoing the process of coach training the participants saw an impact in the areas of development of Listening, Exploring, Understanding and Opening up and Sharing.

\section{Impact on Professional Life}

91.08\% participants during the telephonic interview reported an improvement of Moderate to High impact of coach training on their professional lives. Wherein participants who experienced high impact on their professional life reported highest improvement in the areas of Assumptions, Clarity of Purpose and Emotional States in the pillar of Self-Awareness; In the areas of development of Confidence, Relationships and Empowerment in the pillar of Level Enhancers; and finally, in the areas of development namely Listening, Exploring and Learning from the pillar Level of Functioning.

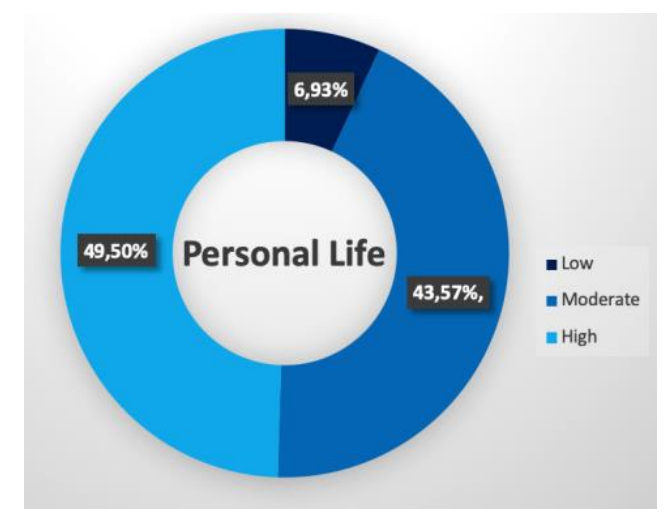

Figure 7: Low, moderate and high impact on the clients' personal life.

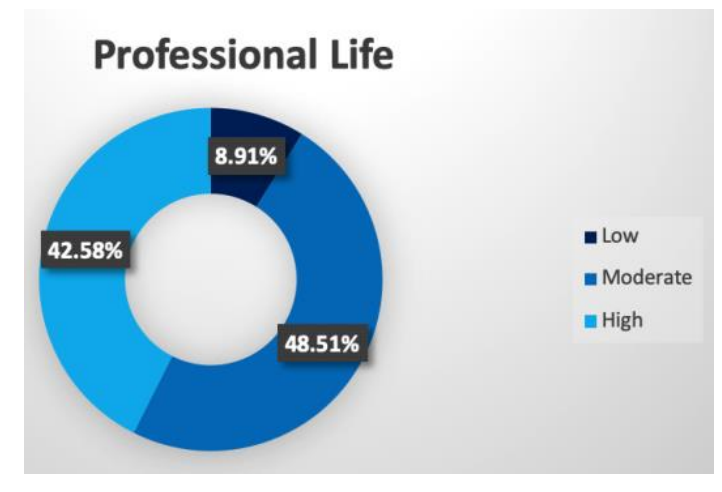

Figure 8: Low, moderate and high impact on the clients' professional life.

\section{Implications}

Leadership, self-awareness and good coaching skills are inextricably interwoven. Coach's personal values \& beliefs certainly shine through his/her actions. Someone who is simply following a checklist and going through the notions of being a coach will quickly 
transmit any scepticism and lack of enthusiasm to the person being coached. So, coaches need to be sensitive of their own behaviour and those of others. Coaches must strike a balance. The survey, explores the immense potential of Coach Training Programs' powerful impact on various areas of development as well as on the individuals' personal and professional life. Coach Training enables people to understand the importance of being Self- Aware. People are able to become more confident and curious in life and are also able to improve their relationships. Coach Training helps people to strive for maximum effectiveness by working at different levels to improve their daily functioning. The results obtained in this survey imply that Coach Training has got the power to transform people into the best version of themselves. Thus the process of coach training can impact an individual's life beyond the coach training process and help them in their journey of self-transformation.

\section{Conclusion}

Therefore, we can conclude that the study shows influence of coach training in various areas of development and how these areas impacted the professional as well as personal life of the coach. The study provides a foundation on how short-term intensive coach training can bring about significant positive impact in a coach's life. The study also highlights the preferred areas of development on which the coach wants to work upon during the process of coach training, with further evidence and support this can be helpful in making the whole process of coach training more focussed and stream-lined according to the requirements of the person being coached. By understanding how the coach training impacts the life of a person in various areas of development in their professional and personal life organisations can train their employees to have a better work life balance as well as create a workforce which is high on emotional quotient thus resulting in better team dynamics which will ultimately improve the productivity and environment of the organisation. Hence this study can provide a foundation to conduct more scientific studies in the field of coaching focussing on how coach training impacts personal and professional lives of the coach and also addressing various areas of development where coach training can make a difference. This study can also be used as a base research to help organisations understand how coach training helps them build a better workforce with high emotional quotient thus helping the organisation grow by creating a safe and positive environment for their employees. The nature of the current study is qualitative as the process of coaching in itself is subjective because of its experiential nature. However, with the development of coaching its impact can be seen in an objective manner thus opening the doors to quantitative research in the field of coaching for the future.

\section{References}

Dai, G., De Meuse, K. P., Lee, R. J., \& Hallenbeck, G. S. (2009). Evaluating the effectiveness of executive coaching: Something to consider. PsycEXTRA Dataset. https://doi.org/10.1037/e518422013-790

De Meuse, K. P., Dai, G., \& Lee, R. J. (2009). Evaluating the effectiveness of executive coaching: Beyond ROI? Coaching: An International Journal of Theory, Research and Practice, 2(2), 117-134. https:// doi:10.1080/17521880902882413

Grant, A. M. (2007). Enhancing coaching skills and emotional intelligence through training. Industrial and Commercial Training, 39(5), 257-266. https://doi:10.1108/00197850710761945

Ibarra, H., \& Scoular, A. (2019, October 25). The Leader as Coach. Harvard Business Review. https://hbr.org/2019/11/the-leaderas-coach.

International Coach Federation. (2016). 2016 ICF Global Coaching Study. Retrieved from https://coachfederation.org/app/uploads/2017/12/2016ICFGlobalCoachingStudy_ExecutiveSummary-2.pdf.

International Coach Federation. (2017). 2017 ICF Global Consumer Awareness Study. Retrieved from https://cplatform-files.s3.useast-2.amazonaws.com/resources/ICF_2017_Survey.pdf

Schlosser, B., \& Steinbrenner, D., Kumata, E. (2007). The Coaching Impact Study: Understanding the Value of Executive Coaching with Commentary. The International Journal of Coaching in Organisations. https://doi.org/10.1037/e519512013005

Turner, E., \& Hawkins, P. (2018). Mastering contracting. Mastering Executive Coaching, 10-25. https://doi.org/10.4324/9781351244671-2

Publisher's Note: SSBFNET stays neutral with regard to jurisdictional claims in published maps and institutional affiliations.

\section{(c) (i)}

(C) 2021 by the authors. Licensee SSBFNET, Istanbul, Turkey. This article is an open access article distributed under the terms and conditions of the Creative Commons Attribution (CC BY) license (http://creativecommons.org/licenses/by/4.0/).

International Journal of Research in Business and Social Science (2147-4478) by SSBFNET is licensed under a Creative Commons Attribution 4.0 International License. 